\title{
GEORGE MOORE: LA PASIÓN FRANCESA ${ }^{1}$
}

\author{
Esther González Alarcón, Universidad de Almería \\ Email: igonzale@ual.es
}

\begin{abstract}
Resumen: Nuestro propósito con este trabajo es dar a conocer la obra del autor irlandés George Moore. Hablaremos de la influencia que tuvo Francia, los pintores impresionistas y escritores franceses de finales del siglo XIX y principios del XX en su carrera de escritor. Tomaremos como análisis de estudio su libro de memorias Confessions d'un jeune anglais (1986) ya que dicha autobiografía es un fiel retrato del espectáculo que se vivía en París durante aquellos años. Sigamos a ese joven por las calles de Montmartre, véamoslo discutir de pintura con Manet y Renoir, oigámosle compartir ideas con Zola y Verlaine...

Palabras clave: Francia, pasión, Montmartre, pintura, literatura.
\end{abstract}

Title in English: George Moore: The French Passion.

Abstract: Our aim with this piece is to introduce the work of the Irish author George Moore. We will speak of the influence which France, the impressionist painters, and the French writers from the end of the 19th century and the beginning of the 20th century, all had on his career as a writer. For research purposes we have chosen his memoirs Confessions d'un jeune anglais (1986) as this autobiography is a true portrayal of the artistic life which was experienced in Paris in those years. We follow this young man through the streets of Montmartre, we see him discuss painting with Manet and Renoir, we hear him share ideas with Zola and Verlaine....

Keywords: France, passion, Montmartre, painting, literature.

El presente trabajo tiene como objetivo dar luz a la vida y obra de George Moore (1852-1933) haciendo mención a su gran pasión: Francia, país en el que vivió durante su juventud y donde descubrió su vocación de escritor.

Vamos a centrar nuestra atención en Cofessions d'un jeune anglais (1986b) y no en Confessions of a Young man (1986a), la versión en inglés, siguiendo las sugerencias que el propio autor nos hace en su prólogo:

Les Confessions of a Young man- un livre assez semblable à celui-ci-ont paru, il est vrai, en Angleterre et en Amérique, et, puisque je renseigne mes lecteurs sur tout ce qui me concerne, on me permettra d'ajouter qu'elles y ont eu quelque succès. Mais, en collaborant à la traduction de l'ouvrage, j'y ai introduit assez de changements et d'additions-même un chapitre entier, le douzième,- pour pouvoir, jusqu'à ce que l'occasion se présente de

Date of reception: 15 June 2011

Date of acceptance: 30 November 2011 
retravailler l'original anglais, considérer la version française comme mon livre plutôt que l'autre ${ }^{2}$ (Moore 1986b: 1).

Las primeras Confessions of a Young man (1986a) las redacta un personaje literario llamado Edwin Dayne, sin embargo en Confessions d'un jeune anglais (1986b) ese personaje desaparece para dejar sitio al escritor, de ahí que la obra esté redactada en primera persona. En ella, George Moore, nos abre y nos desvela con orgullo su "yo" interno y nos muestra el París de finales de siglo que él vivió.

Tras este viaje a la capital francesa, en donde Moore disfrutó de una etapa de pasión, de gloria y prestigio, hablaremos de la influencia que tuvo en su producción literaria posterior, su paso por tierras galas así como los escritores y pintores que allí conoció. Para ello mencionaremos en primer lugar su intensa y poco exitosa experiencia como pintor impresionista. Seguidamente abordaremos la faceta, fugaz, de George Moore como poeta (tras la lectura de Les Fleurs du Mal) y finalmente concluiremos aplaudiendo su decantación final en el mundo de las letras, la prosa, donde Moore sentó cátedra. En este sentido pensamos que las relaciones personales que mantuvo con los novelistas franceses de la época fueron pieza clave en esta elección final.

George August Moore, nace un 24 de febrero de 1852 en Moore Hall, al borde del lago Carra, sobre una colina rodeado de un mar verde...en Irlanda, en medio de un entorno donde los sueños encantados se vuelven protagonistas, un lugar que siempre tendría presente nuestro escritor irlandés.

Pasó una feliz, libre e indisciplinada infancia en la que disfrutó de largos ratos fuera de casa con su hermano Maurice. Sin embargo, sus padres deciden enviarlo a la edad de nueve años como alumno interno al St. Mary's College, una escuela de Oscott. En este "Eton" católico ya demuestra ser un joven poco interesado en los estudios.

De vuelta del St. Mary's College y sin ningún título en mano, nombran al padre de George Moore, Georges Henry Moore, miembro del Parlamento Independiente en la Cámara de los Comunes del Reino Unido. Su madre comprende que ante tal investidura toda la familia debe abandonar Irlanda y emigrar a Londres. Es el año 1868. En la nueva ciudad, el padre intenta, sin éxito, que su hijo siga la carrera militar. Sin embargo, George decide frecuentar los talleres de pintura de Londres y es dentro de este entorno donde coincide con Jim Brown, un viejo amigo de la familia, quien le aconseja que se marche a París si su deseo es triunfar en ese arte.

Moore cuenta con tan sólo doce años de edad cuando su padre fallece en 1870. La muerte de su progenitor al que ama profundamente es, paradójicamente, una liberación que le permite arrancar todos los lazos que le sujetaban, "La mort de mon père me délivrait, et je m'élançai, comme une branche retenue à terre, vers la lumière"’3 (1986b: 8). Después de

\footnotetext{
2 "Las Confessions of a young man - libro muy parecido a éste, se publicó, es verdad, en Inglaterra y en América, y ya que informo a mis lectores de todo lo que me atañe, que se me permita decir que ha tenido bastante éxito. Pero, al colaborar en la traducción de la obra, he introducido bastantes cambios y añadidos -hasta un capítulo entero, el capítulo doce,- para poder considerar la versión en francés, hasta que se presente la ocasión de volver a remodelar el original en inglés, como mi libro" (1986b: 1).

- Todas las citas han sido traducidas por la autora del artículo-

3 "La muerte de mi padre me liberaba, y me arranqué, como una rama sujeta a la tierra, hacia el sol" (1986b: $8)$.
} 
ese renacer, nadie lo puede retener y el exilio a Francia parece la continuación natural de esa búsqueda de sí mismo. Libre de toda autoridad familiar, rico, el joven Moore se siente irresistiblemente atraído por ese país:

Mais si vous voulez être peintre, il vous faut aller en France... La France est la seule école des arts. De nouveau j' appelle l'attention sur le phénomène de "l'écho prophétique", c'est-à-dire de paroles entendues par hasard et qui, sans que notre raison s'en mêle, amènent inévitablement la croyance. La France! Tous mes sens bondirent hors du sommeil, comme un équipage quand la vigie crie: “terre en avant !" Sur-le-champ, je vis que j'irais, que je devais aller en France, que je voulais y vivre, que je voulais devenir Français. Je ne savais ni quand ni comment, mais je savais que j'irais en France... ${ }^{4}$ (1986b: 8-9).

París era una fiesta. La fiesta del arte y del talento: pintores, poetas y escritores irradiaban en Europa, cultura y modernidad ${ }^{5}$. Era el principio de la III $^{\mathrm{a}}$ República y George Moore llega a París ${ }^{6}$ dos años después de la sangrienta represión de la Comune parisina.

La presentación de la Gare du Nord es, aún hoy, perfectamente válida y despierta en el lector una imagen que se asemeja a un cuadro impresionista:

Enfin le jour arriva, et, avec plusieurs malles et caisses pleines de vêtements, de livres et de tableaux, je partis, accompagné d'un valet anglais, pour Paris et pour l'Art. Nous connaissons tous la vaste gare du Nord, grise et mélancolique à six heures et demie du matin, la ville hagarde: des maisons pâles, boueuses et jaunes, une absence de couleur qui oppresse, un horrible froid matinal particulier aux rues de Paris. En bas, sur l'asphalte, la ménagère se hâte ; un garçon de café, avec une serviette nouée autour de la gorge, remue quelques chaises, si décrépites et si solitaires qu'il est impossible de s'imaginer un être humain assis là. Où sont les boulevards ? Où sont les Champs-Élysées?7 (1986b: 16).

\footnotetext{
4 "Pero si quiere ser pintor, tiene que irse a Francia Francia es la única escuela de Arte. De nuevo, me llama la atención el fenómeno del "eco profético", es decir, las palabras oídas por casualidad, y que sin que la razón tome consciencia de ello, nos marcan. ¡Francia! Esa palabra sonó en mis oídos y destelló ante mis ojos. ¡Francia! todos mis sentidos saltaron fuera del sueño, como lo hace la tripulación cuando el vigía grita "¡tierra a la vista!". Inmediatamente supe que debía ir a Francia, que allí quería vivir y que quería ser francés. No sabía cómo ni cuándo pero sabía que iría a Francia" (1986b: 9).

5 There can be general agreement that Confessions of a Young Man, written many years after Moore's arrival in Paris in 1873, discusses events, the arts and literatures, science and religion, and many other issues of that time and place. In this sense, it is a true document of the history of the last two decades of the nineteenth century [...] Confessions of a Young Man is a protrait of that spectacle in Paris (Pierse 2006: 75-76).

"He arrives in Paris, not as a poor, lonely young man (as were Joyce, Beckett and others) but "with several trunks, books and pictures" and an English valet [...] Following his arrival, he savours the decadent life of the end of the century, end of an age, and end of an Empire. Since its publication in 1857, Baudelaire's Fleurs du Mal had defined the mood of "end", "fall", "decadence". Sthéphane Mallarmé's "Plainte d'Automne" (1864), illustrates that mood and its translation by Moore both catches the flavour of the moment and provides a key to reading of Confessions of a Young Man" (Pierse 2006: 78).

7 "Finalmente llegó el día, y con varios baúles y cajas llenos de ropa, de libros y de cuadros, salí acompañado por un sirviente inglés, hacia París y el Arte. Todos conocemos la vasta estación del Nord, gris y melancólica a las seis y media de la mañana, una ciudad azorada: casas pálidas, sucias y amarillas, una ausencia de color que oprime el corazón, un frío horrible muy particular de las calles de París. Más abajo, por el asfalto, el ama de casa se da prisa, un camarero, con una servilleta anudada en la garganta, mueve algunas sillas, tan decrépitas y solitarias que es imposible imaginarse a un ser humano sentado ahí. ¿Dónde están los bulevares? ¿Dónde están los Campos Elíseos?” (1986b: 16).
} 
Todo lo que es galo le entusiasma, al principio la lengua francesa se le resiste ${ }^{8}$, pero está decidido a integrarse en esa sociedad que tanto le atrae y al cabo de muy poco tiempo ya es capaz de hacerse comprender:

... je fus obligé d'attendre trois semaines avant de pouvoir soutenir une conversation en français. Comment j'accomplis cet exploit, je ne puis le dire; je sais que je n'ouvris jamais un livre; et il n'est pas agréable de songer à quoi devait ressembler mon langage, probablement à rien qui ait été entendu jusque-là sous le ciel de Dieu ${ }^{9}$ (1986b: 17).

Nada ni nadie podrá amilanar a Moore cuando los sentimientos por un lugar son tan intensos y pasionales, porque el irlandés se ha enamorado de esa tierra y no es un amor pasajero. Con paso decidido se adentra en el París de los cafés ${ }^{10}$ extraños y misteriosos de la mano de su amigo el pintor Marshall ${ }^{11}$ con el que practica la capacidad de observación que le caracteriza (es verdad que no domina totalmente la lengua y así es más fácil centrarse en esos personajes parisinos que tanto le interesan y es en esa mirada donde vemos más al escritor que al pintor "Cette soif d'observer les moeurs, cet instinct d'une notation rapide des gestes qui résument l'âme et des attitudes qui reflètent la pensée, se déclara en moi comme une passion véritable") ${ }^{12}$ (1986b: 17). Los cafés, lugares de reunión de todos los artistas de la época, son como los salones literarios del siglo XVIII ${ }^{13}$ y como tales se les considera. Moore así lo cuenta:

Je ne suis allé ni a Oxford ni a Cambridge, mais je suis allé à la Nouvelle Athènes. Qu'est-ce que c'est que la Nouvelle Athènes ? Celui qui désire connaître quelque chose de ma vie, doit connaître quelque chose de l'académie des Beaux-Arts. Non pas cette stupide institution officielle dont on parle dans les journaux quotidiens, mais la véritable académie française, le café. La Nouvelle Athènes est un café de la place Pigalle [...] Comme ces souvenirs de jeunesse sont vifs, magnétiques et vivifiants ! avec quelle clarté étrange, presque surnaturelle, je vois la figure pâle de ce café, le nez blanc de ce bloc de maisons arrivant à la place, entre deux rues. Je vois jusqu'au fond de la pente de ces deux rues, et je sais les boutiques qui s'y trouvent, J'entends la porte vitrée du café grincer sur le sable quand je l'ouvre. Je me rappelle l'odeur de chaque heure; le matin, celle des œufs cuisant

\footnotetext{
8 "When the two travelers had arrived at the Gare du Nord in mid-March, three months earlier, GM read his French dictionary on the way to the Hôtel Quai Voltaire, but he did not have enough French to ask for a room, hot water, and a fire" (Frazier 2000: 27).

9 "Tuve que esperar tres semanas antes de poder mantener una conversación en francés. No es agradable pensar a qué podía parecerse mi lenguaje, probablemente a nada que, hasta ese momento, se hubiese oído bajo el cielo de Dios" (1986b: 17).

10 Los cafés que más frecuentó Moore son : el Café du rat mort en Pigalle situado enfrente del café de La Nouvelle-Athènes en el que dice Moore está enraizado el pensamiento artístico del siglo XIX y en el que se creó el periódico fundador del movimiento impresionista. Esos cafés eran lugar habitual de reunión de los escritores y poetas como Zola, Maupassant, Mallarmé, Baudelaire así como de los pintores Degas, Pissarro, Manet, Cézanne, Sisley o Renoir.

11 Su verdadero nombre era Lewis Weldon Hawkins.

12 "Esa sed de observar las costumbres, ese instinto de tomar nota rápidamente de los gestos que resumen el alma y la actitudes que reflejan el pensamiento, surgieron en mí como una verdadera pasión" (1986b: 17).

13 Los Salones franceses del siglo XVIII, característicos de la Ilustración, eran lugar de encuentro de las principales figuras de este movimiento, no sólo escritores -Montesquieu, Fontanelle, Voltaire, Diderot...-sino también políticos, filósofos como Rousseau, Hume, etc. que acudían al París del siglo XVIII.
}

Odisea, ${ }^{\circ} 12$, ISSN 1578-3820, 2011, 319-329 
dans le beurre, celle de l'âcre cigarette, du café et du mauvais cognac ; à cinq heures, l'odeur végétale de l'absinthe ; bientôt après, on monte de la cuisine la soupe fumante, et à mesure que la soirée s'avance, ce sont les odeurs mêlées des cigarettes, du café et de la petite bière [...] Les tables de marbre habituelles sont là ; là nous avions l'habitude de nous asseoir et de faire de l'esthétique jusqu'à deux heures du matin ${ }^{14}$ (1986b: 104-105).

Cuando se abre la puerta del café entran Villiers de l'Île Adams, Degas, Manet, Catulle Mendés o Pissarro. Moore describe con humor, cariño o admiración su físico, los gestos o las manías y los lectores tenemos la impresión que casi los hemos conocido...

Él mismo confiesa su propia falta de sensibilidad hacia ese tipo de pintura hasta que no tomó conciencia de la belleza de los temas y del arte de esos pintores tan odiados y objeto de tantas burlas. Moore relata sus primeras sensaciones cuando se abre al público la primera exposición impresionista ${ }^{15}$ con pinturas de Pissarro, Cezanne, Monet (y no Manet, que se niega a exponer y nunca aceptó ser impresionista), Degas, Sisley, Berthe Morisot, Guillemin y Renoir. Reconoce haberse mofado de todos ellos, y lo confiesa con humildad. Cuenta la crítica que hace a cada uno de los cuadros de esos artistas que, con los años, admirará, y los analiza como un pintor que nunca dejó de ser: Degas y sus mujeres desnudas, Pissarro y su grupo de chicas jóvenes recogiendo manzanas en un jardín, Morisot con sus mujeres en los balcones, Guillaumin y sus mujeres pescando en un parque, Monet y los Pavos, Renoir y su arte para transmitir la vida en un cuerpo joven y sobre todo los colores de la vida en la naturaleza:

Nous ne savions que lancer de grossières railleries: Qu'est-ce qui avait pu l'amener à peindre de telles choses ? Certainement il devait avoir vu que c'était absurde, je ne sais pas si les impressionnistes sont sérieux ou si c'est seulement une blague qu'on nous fait? [...] Car l'art n'était pas pour nous alors ce qu'il est maintenant: une pure émotion, vraie ou fausse, uniquement selon son intensité ; nous croyions à la grammaire de l'art, à la perspective, à l'anatomie... ${ }^{16}$ (1986b: 45-46).

\footnotetext{
14 "No he ido ni a Oxford ni a Cambridge, pero he ido a la Nouvelle-Athènes. ¿Qué es la Nouvelle Athènes? El que desee conocer algo de mi vida, debe conocer algo de la academia de Bellas-Artes. No esa estúpida institución oficial de la que se habla en los periódicos cotidianos, sino la verdadera academia francesa, el café. La Nouvelle-Athènes es el café de la plaza Pigalle [...] iQué vivos están esos recuerdos de juventud! Con qué extraña claridad, casi sobrenatural, veo la cara pálida de ese café, la nariz blanca de ese bloque de casas adentrándose en la plaza, entre dos calles. Veo hasta el final de la cuesta de esas dos calles, y conozco las tiendas que hay allí. Cuando abro la puerta acristalada la oigo chirriar por culpa de la arena. Recuerdo el olor de cada hora; por la mañana, el de los huevos friéndose en mantequilla, el agrio del cigarrillo, del café y del coñac malo, a las cinco, el olor vegetal de la absenta; poco después suben la sopa humeante de la cocina, y a medida que el tiempo va pasando los olores mezclados con los cigarrillos, el café y la cerveza mala. [...] las mesas habituales de mármol están ahí; ahí teníamos la costumbre de hablar de estética hasta las dos de la madrugada" (1986b: 104-105).

15 La primera exposición impresionista tuvo lugar en París del 15 de abril al 15 de mayo de 1874.

16 "Sólo sabíamos burlarnos de manera grosera . ¿Que le ha pasado para pintar tales cosas?. Tenía que saber que era absurdo, no sé si los impresionistas son serios o si nos están gastando una broma [...] Entonces el arte no era para nosotros lo que es hoy: pura emoción, verdadera o falsa según su intensidad; creíamos en la gramática del arte, en la perspectiva, en la anatomía..." (1986b: 47).
} 
George Moore siempre reconoce sus errores y los expone públicamente sin miedo al ridículo. Con una pluma ágil de escritor "impresionista" nos describe a Manet, su amigo y maestro “... et Manet entra. Bien qu'essentiellement Parisien, par la naissance et par l'art, il y avait dans sa physionomie et ses manières quelque chose qui le faisait ressembler à un anglais. Peut-être était-ce ses vêtements-ses habits à la coupe élégante. Cette tournure !... ces épaules carrées..."17 (1986b: 109). Degas: "Cet homme aux épaules raides, vêtu d'une costume poivre-sel. Il n'y a rien chez lui qui soit français d'une façon bien tranchée, excepté sa cravate. Ses yeux sont petits, ses paroles sont incisives, ironiques, cyniques. Ces deux hommes sont les deux chefs de l'école impressionniste"18 (1986b: 110).

Pero nuestro escritor también "se integra" en las clases sociales más peligrosas para un joven irlandés sin experiencia, como la de las demi-mondaines o la de los proxenetas que tan originales le parecían. Las demi-mondaines o prostitutas de lujo tenían un papel importante en la sociedad parisina de finales del siglo XIX. Ser un hombre rico en esa época era poder exhibir una de esas mujeres hermosas que rompían los corazones de los jóvenes bohemios. "Nous montions et descendions à plaisir les barreaux de l'échelle sociale. Nous passions par exemple une soirée chez Gontrant, rue de la Gaité, en compagnie de voleurs ou de souteneurs, et la soirée suivante avec une duchesse ou une princesse aux Champs-Élysées"19 (1986b: 47). Sin problemas económicos, el joven que parece, según Manet el gran pintor y amigo suyo ${ }^{20}$, "una yema de huevo aplastada" decide ser pintor y vivir como tal. Pero a ese gentleman rubio y distante no se le da bien la pintura, él mismo lo reconoce:

Mon dessin n'était jamais commun ; il était d'un sentiment original ; il était épuré. Je possédais toutes les qualités rares, mais non la force initiale sans laquelle tout le reste n'est rien: -je veux dire le talent de l'enfant qui saisit et trace à grands traits la caricature de son maître d'école ou l'esquisse vivante de son cheval favori sur la porte de l'écurie avec un morceau de craie ${ }^{21}$ (1986b: 49).

George es ya un completo parisino totalmente integrado en la alta élite social de la capital francesa del Segundo Imperio. Sin embargo, su gran ilusión, la carrera de pintor, el motivo por el que un día decidió trasladarse a París, jamás vería la luz. Él mismo,

\footnotetext{
17 “-... y Manet entró. Aunque esencialmente parisino, por nacimiento y por arte, tenía algo en su fisico y sus maneras que le hacían parecer inglés. Podía ser su ropa- su ropa de corte elegante- y su físico ¡Ese cuerpo!... sus hombros anchos..." (1986b: 109).

18 "Ese hombre de hombros rígidos, con un traje gris. No hay nada en él que sea francés de manera clara, exceptuando su corbata. Sus ojos son pequeños, sus palabras incisivas, irónicas, cínicas. Esos dos hombres son los jefes de la escuela impresionista" (1986b: 110).

19 "Bajábamos y subíamos, a placer, la escala social. Pasábamos una velada en Gostrant, calle de la Gaieté, en compañía de ladrones y proxenetas, y la velada siguiente con una duquesa o una Marchesa en los Campos Elíseos" (1986b: 47).

20 Edouard Manet pintó dos retratos de Moore en 1879. El primero inacabado que no gustó y el segundo, conocidísimo que tampoco gustó a Moore pero que parece ser fiel al modelo.

21 "Mi manera de dibujar no era nunca común, tenía un sentimiento original, era puro. Poseía todas las cualidades raras, pero no la fuerza inicial sin la cual nada existe: quiero decir el talento del niño que comprende y dibuja a grandes rasgos la caricatura de su maestro de escuela o el esbozo vivo de su caballo favorito en la puerta de la cuadra con una tiza" (1986b: 49).
}

Odisea, ${ }^{\circ} 12$, ISSN 1578-3820, 2011, 319-329 
convencido de la inutilidad de sus esfuerzos, decide abandonar el pincel para siempre y entregarse a la literatura. ${ }^{22}$

Para comprender la literatura francesa del siglo XIX es absolutamente imprescindible leer a George Moore. En su libro de memorias Confessions d'un jeune anglais (1986b) están los escritores franceses más célebres de la época. En él los vemos discutir en los cafés, ir al teatro o a lugares más comprometidos o simplemente comportarse como simples humanos con sus defectos y sus virtudes. La admiración de Moore, casi siempre pasajera por los artistas franceses, es a menudo ingenua. Sólo Honoré de Balzac escapa a esa decepción y Moore jamás se sentirá decepcionado por su autor francés preferido. Él, al que se le acusa de haber quemado lo que adoró, salvó a Balzac de entre todos:

De tous ceux que j'ai profondément aimés, il n'en est qu'un qui puisse m'inspirer l'ancienne passion, l'extase d'autrefois,- c'est Balzac. Sur ce rocher j'ai bâti mon église et son grand et valide talent m'a sauvé des eaux envahissantes de la nouvelle esthétique, de la boue âcre et malsaine du symbolisme. En pensant à lui, je ne pouvais oublier que c'est l'esprit et non la chair qui est éternelle [...] Mais j'avoue- si la supériorité inhérente de la poésie sur la prose, supériorité que j'admets sans hésiter, est mise de côté- qu'il m'est littéralement impossible de voir en quoi Shakespeare est plus grand que Balzac [...] Balzac fut la grande influence morale de ma vie ; le point culminant de mes lectures fut la Comédie humaine ${ }^{23}$ (1986b: 103).

La obra de Théophile Gautier Mademoiselle de Maupin (2004) le abre la mente a otro tipo de literatura y ya no se siente tan solo en su desprecio de la religión, una religión que aborrece desde su infancia ' $L$ 'Angleterre est le protestantisme, et le protestantisme est fort, propre et occidental; le catholicisme ressemble à un eunuque; il est sale et oriental..."24 (1986b: 119).

Sólo después de varias lecturas reconoce en Musset a un poeta. Baudelaire le entusiasma de inmediato con sus Fleurs du Mal (2004), flores en las que más tarde se inspirará para escribir Flowers of Passion (1978) (con poco éxito) y al que admira profundamente. Ese tipo de literatura que siente como una pasión será descrita en su obra Confessions d'un jeune anglais (1986b) como una literatura loca e insana. ¿Pero qué tiene esta literatura "loca" y "perversa" que tanto enamora a George Moore?

\footnotetext{
22 En realidad fue Jullian, su maestro pintor, quien comenzó a inculcar a George Moore, inconscientemente y sin ninguna intención, el mundo de los escritores franceses de finales del Siglo XIX, por medio de esas charlas que les daba, en los descansos después de unas largas sesiones de pintura y en donde les contaba sus primeros años en París y sus primeras lecturas, Balzac, del que hablaba con mucho ímpetu (Collet 1957: 8).

23 "De todos los que he amado profundamente, sólo uno puede despertar mi vieja pasión, el éxtasis de antaño ,-Balzac. Sobre esa piedra construí mi iglesia y su grande y valioso talento me ha salvado de la destrucción, me ha protegido de las aguas invasoras de la nueva estética, del lodo pútrido del naturalismo y de la espuma agria e insana del naturalismo. Pensando en él, no podía olvidar que el espíritu, y no la carne, es eterno [...] Pero reconozco -si la superioridad inherente de la poesía sobre la prosa, superioridad que admito sin titubear, se pone de lado- que me es literalmente imposible ver en qué es superior Shakespeare a Balzac [...] Balzac fue la influencia moral más grande de mi vida; el punto culminante de mis lecturas fue la Comedia humana" (1986b: 103).

24 "Inglaterra es el protestantismo, y el protestantismo es fuerte, limpio y occidental, el catolicismo se parece a un eunuco; es sucio y oriental" (1986b: 119).
} 
Baudelaire, el poeta maldito, a través de The Flowers of Evil, nos presenta la visión que éste tiene del hombre, de él mismo y de la realidad que lo mantiene encerrado. Nuestro poeta francés siente esta realidad como un desgarro del alma, un sufrimiento insoportable. George Moore, tras su derrota como pintor, experimentará el mismo desasosiego (1986b: 64).

En su afán por integrarse en la sociedad francesa lee, a menudo sin ningún hilo conductor, a los poetas y escritores reconocidos. ${ }^{25}$ No puede obviar a Victor Hugo pero éste le aburre y el irlandés le critica ferozmente, para gran escándalo de sus lectores franceses ya que es el autor más reconocido y admirado de Francia:

Hugo! Comme il est impossible de parler de la littérature française sans faire allusion à lui! Concluons cependant ; il pensait qu'en disant tout et en répétant vingt fois, il rendrait à jamais impossible l'arrivée d'un autre grand poète. Mais un ouvrage d'art a de la valeur et fait plaisir proportionnellement à sa rareté: un beau livre de vers vaut mieux que vingt beaux livres de vers. C'est là une vérité absolue et incontestable ; un enfant peut se moquer de cette vérité: qu'un vers est préférable au poème tout entier, un mot préférable au vers, une lettre préférable au mot ; mais la vérité n'est pas affectée par cela. Hugo n'a jamais eu la bonne fortune d'écrire un mauvais livre, ni même un seul mauvais vers ; aussi, n'ayant pas le temps de tout lire, la postérité n'en lira aucun. Quelle immortalité ne gagnerait-il pas par la destruction de la moitié de ses ouvrages! ${ }^{26}$ (1986b: 67-68).

Sus notas, escuetas a veces otras veces larguísimas y enrevesadas, humanizan a esos célebres escritores a los que presenta con sus defectos y virtudes: "Leconte de Lisle me répugna du premier abord; [...] je ne m'étais pas trompé; tout ce à quoi je m'attendais, je le trouvai: long, désolé, fatiguant, Leconte de Lisle produit sur moi l'effet d'une promenade à travers le palais de justice..." ${ }^{27}$ (1986b: 66). Así sigue una larga lista: Coppée, Mendés, José María de Heredia... Cada uno es analizado con severidad o con tolerancia pero ninguno escapa al humor, sarcasmo algunas veces, de Moore que también sentencia sin contemplaciones al simbolismo "Mais en quoi consiste le symbolisme? Vulgairement parlant, à dire l'opposé de ce que vous voulez dire !"28 (1986b: 73). Su antigua pasión, el naturalismo con $Z \operatorname{la}^{29}$ a la cabeza, no tarda en seguir el mismo camino, ese naturalismo que le encandila al poco tiempo de llegar a Francia y que considera como la verdad, el nuevo

\footnotetext{
25 Del mismo modo que con anterioridad Moore examinó, siempre detenidamente, los cuadros de los impresionistas franceses, ahora analizaba las páginas y páginas de los simbolistas y los naturalistas franceses. 26 “¡Hugo! ¡Es imposible hablar de literatura sin hablar de él! Para terminar: él pensaba que diciéndolo todo y repitiéndolo veinte veces, imposibilitaría para siempre la llegada de otro gran poeta. Pero una obra de arte tiene valor y produce placer en proporción a su rareza: un hermoso libro de poesía vale más que veinte hermosos libros de poesía. Eso es una verdad absoluta e indiscutible; un niño puede reírse de esa verdad: de que un verso es preferible al poema entero, una palabra preferible a un verso, una letra preferible a una palabra: pero eso no afecta a la verdad. Hugo no ha tenido nunca la suerte de escribir un libro malo, ni siquiera un verso malo, así pues la posteridad no pudiendo leerlos todos, no leerá ninguno. ¡Cuánta inmortalidad no ganaría si destruyera la mitad de su obra!"” (1986b: 67-68).

27 "Leconte de Lisle me repugnó [...] no me equivoqué, todo lo que esperaba lo encontré, me pareció: largo, desolador, cansino, Leconte de Lisle produce en mí el mismo efecto que un paseo por un palacio de justicia..." (1986b: 66)

${ }_{28}$ “En qué consiste el simbolismo? Vulgarmente hablando en decir lo contrario de lo que quiere decir en realidad..." (1986b: 73).

${ }_{29}$ "Lo que le reprocho a Zola es que no tiene estilo..." (1986b: 120).
} 
arte. El joven que parece un verdadero dandy es invitado a las Soirées du jeudi de Mallarmé, a Médan también. Su crítica a los Goncourt se puede tachar casi de cruel “Goncourt n’est pas un artiste, malgré toute son affectation et ses prétentions. Ce n'est pas un artiste. Il me fait l'effet d'une vieille dame en quête de l'immortalité..." ${ }^{30}$ (1986b: 127).

Moore se ríe de lo que llama "excentricidades del lenguaje" de Arthur Rimbaud y conocer a Rimbaud es conocer a Verlaine. Ese "poeta maldito" le descubre el mundo de la poesía, esa poesía hecha de dolor y angustia, de spleen y de drogas, lo que para él será la poesía:

Baudelaire sur un orgue du moyen-âge exaltait son incrédulité et sa haine de la vie. Mais Verlaine allait plus loin; la haine lui est lieu commun aussi bien que l'amour, l'incrédulité aussi vulgaire que la foi [...] ni dans Baudelaire, ni même dans Poe, on ne peut trouver de poésie plus belle. Poe, toi qui demeure non lu et non compris en Amérique et en Angleterre, ici tu fais partie intégrante de la vie artistique ${ }^{31}$ (1986b: 76).

Otros maestros, muestra de la extensa cultura literaria de Moore, merecen todo su respeto como La Rochefoucaud y Pascal, aunque no le parezcan muy interesantes por estar tan lejanos en el tiempo. Moore sabe, y así lo escribe, que su carrera de escritor debe mucho a su experiencia parisina. Allí conoció a todos los poetas y escritores que le formaron en el difícil arte de la literatura. Allí se perdió un pintor y se ganó un escritor, allí encontró su destino. Siempre honesto consigo mismo, Moore reconoce sus defectos y sabe que no es fiel a sus primeros amores literarios. Con los años va cambiando de pasiones pero, así lo expresa, es inherente a su carácter el querer un día y odiar otro, lo que tanto amó:

Je suis un sensualiste en littérature; je puis voir parfaitement que tel ou tel libre est une oeuvre de génie, mais s'il “ ne me touche pas", il n'a rien à faire avec moi et j'oublie jusqu'à son existence. Ce qui me laisse froid aujourd'hui me rendrait fou demain. Avec moi la littérature est une question de sensation, de sensation intellectuelle si vous voulez, mais de sensation malgré tout, et réglée par des caprices aussi violents que ceux qui gouvernent la chair [...] Shelley, Gautier, Zola, Flaubert, Goncourt ! comme je vous ai aimés tous ! et maintenant je ne pourrais pas, je ne voudrais pas vous relire ${ }^{32}$ (1986b: 99-100).

Después de siete años en los que George Moore se siente casi francés, un problema con sus granjeros le obliga a regresar a su país. Francia pierde un escritor que dominaba ya perfectamente su idioma hasta el punto de tener dificultades para escribir en su lengua materna:

\footnotetext{
30 "Goncourt no es un artista, a pesar de su amaneramiento y sus pretenciones. No es un artista. Se parece a una anciana [...] en busca de la inmortalidad" ( 1986b: 127)

31 "Baudelaire con un órgano de la Edad Media exaltaba su incredulidad y su odio a la vida. Pero Verlaine iba más allá; el odio es para él un lugar común al amor, y la incredulidad tan vulgar como la fe [...] ni en Baudelaire, ni siquiera en Poe, podemos encontrar una poesía tan bella. Poe, tú que continúas sin ser leído y sin ser comprendido en América y en Inglaterra, aquí formas parte integrante de la vida artística" (1986b: 77-78).

32 "Soy un sensualista en literatura, soy capaz de ver que tal o cual libro es una obra genial, pero si "no me llega" no hay nada que hacer y olvido que existe. Lo que hoy me deja frío, mañana me puede volver loco. En mí la literatura es cuestión de sensación, de sensación intelectual, pero sensación a pesar de todo, y regulada por caprichos tan violentos como los que gobiernan la carne [...] ¡Shelley, Gautier, Zola, Flaubert, Goncourt cuánto os he amado a todos! Y ahora, no podría, no quisiera volveros a leer" (Moore, 1986b: 127).
} 
J'ai entendu citer des gens qui écrivaient et parlaient deux langues ; cela m'était impossible et je suis convaincu que si j'étais resté deux années de plus en France je n'aurais jamais été capable d'identifier mes pensées avec la langue que j'écris maintenant, et j'aurais écrit ma langue maternelle comme une langue étrangère ${ }^{33}$ (1986b: 45-46).

Estos años de vida bohemia en Francia y en los cafés de París dejaron una huella imborrable en su producción literatura posterior.

Tras el fracaso como poeta, Moore, decide orientar su pluma hacia el periodismo con el fin de obtener ingresos económicos. En estos artículos Moore plasmaría todos sus conocimientos sobre el impresionismo que aprendió en París. Así, en 1891, vio la luz en Londres, la recopilación de un buen número de éstos en el tomo Impressions and Opinions. En 1893, un nuevo volumen, Modern Plainting vendría a sentar cátedra sobre el impresionismo francés.

Por otro lado las relaciones personales que mantuvo en París con Zola, los Goncourt, Daudet, Catulle Mendès o Coppée Heredia fueron fundamentales en su decantación final por la prosa. Moore traería importadas de Francia las teorías estéticas imperantes del momento a las Islas Británicas. Trabajó el Realismo así como el Naturalismo. En sus novelas se rastrea la influencia de Zola, del cual se proclamó discípulo, así como el influjo de Flaubert y de Balzac, entre otros. Del mismo modo sus vivencias en París como pintor y con los impresionistas del momento impregnarán toda su obra:

En su primera novela A Modern lover (1883), Moore cuenta las peripecias de un joven artista de poco éxito que alcanza un cierto estatus social, riqueza y gloria por medio de tres mujeres que luego abandona una vez que consigue sus propósitos. En esta obra veríamos reflejado las vivencias de George Moore en el París de finales de siglo.

En A Mummer's Wife (1885) se palpa el Realismo francés de Zola y Flaubert. La protagonista, Kate Ede, al igual que Madame Bovary, fue una fiel seguidora de la literatura romántica en su juventud. Ante la indiferencia total y absoluta de su esposo, inicia una relación con Dick Lennox, un actor, intentando escapar de la mediocridad que la rodea. Sin embargo Dick también la decepcionará, hecho que la conducirá a la bebida, a una vida llena de miseria, a la enfermedad y a una muerte desgraciada. Con esta obra Moore, saltándose los principios del puritanismo literario, acercó el Naturalismo al público británico. Esta novela supuso toda una revolución principalmente para el sector más conservador que expresó su más enérgica repulsa contra la temática de esta obra.

En 1894 el autor publica Esther Water, una obra de influencia naturalista. El libro cuenta la historia de Esther, una madre coraje que saca adelante con mucho sacrificio a su hijo ilegítimo. Con pinceladas flaubertianas, Esther Water llevó definitivamente a Moore a la cima de la celebridad.

Sus amigos y familiares pasaron a ser los personajes de las novelas que lo portaron a la gloria. Sin embargo el personaje preferido de su obra fue él mismo como nos lo demuestran

\footnotetext{
33 "He oído hablar de gente que escribían y hablaban dos lenguas; para mí era imposible y estoy convencido de que si me hubiese quedado dos años más en Francia no hubiese sido capaz de identificar mis pensamientos con la lengua con la que escribo ahora y hubiese escrito mi lengua materna como en una lengua extranjera (1986b: 158)".
}

Odisea, ${ }^{\circ} 12$, ISSN 1578-3820, 2011, 319-329 
sus numerosas autobiografías: Confessions of a Young Man $^{34}$ (1886), Memoirs of My Dead Life (1906), Avowals (1919), Conversations in Ebury Street (1924), Hail and Farewell (1925) y A Communication to my Friends (1933).

Los historiadores de la literatura situaron a George Moore a la altura de Joseph Conrad, Virginia Wolf, James Joyce, Arnold Bennet, D.H. Lawrence, Aldows Huxley, H. G. Wells y John Galsworthy (Butt 1947: 549). De hecho Adrien Frazier manifiesta que la narrativa inglesa moderna no hubiese sido igual sin la presencia en ella del escritor irlandés (2000: 460).

Haciendo un recuento de toda su producción literaria mencionada en este trabajo, así como la aportación que éste hizo al mundo de las letras, introduciendo las corrientes literarias francesas de la época en la literatura en lengua inglesa, no comprendemos por qué se ignora a este autor en muchos países, entre ellos España. Somos conscientes de que aún no se le ha hecho justicia, de otro modo no se entiende que sus libros hayan sido pieza fundamental en la historia de la literatura en lengua inglesa y que los críticos literarios no hayan investigado más sobre su obra.

Con nuestra aportación difundimos su obra y su amor por Francia...su gran pasión, país donde descubrió su vocación de escritor, un lugar que siempre será su patria porque así lo deseó intensamente, una tierra que lo acogió y lo formó en el arte tan difícil de la escritura. Nuestro autor fue muy feliz en Francia, y Francia, aún hoy, está orgullosa de su hijo irlandés que tan bien la comprendió y en donde tanto prestigio alcanzó.

Considérese nuestro trabajo como un homenaje a George Moore, tan ignorado y silenciado hoy por el mundo de las letras.

\section{REFERENCIAS BIBLIOGRÁFICAS}

Baudelaire, CH. 2004. Les Fleurs du Mal. Paris: Gallimard.

ButTs, R.F. 1947. A Cultural History of Education. New York: McGraw-Hill Book Company.

Collet, G.P. 1957. George Moore et la France. Genève: Droz.

Frazier, A. 2000. George Moore 1852-1933. New Haven and London: Yale University Press.

Gautier, T. 2004. Mademoiselle de Maupin. Paris: Gallimard.

Gerber, H. E. ed. 1988. George Moore on Parnassus. Newark: University of Delaware Press.

Moore, G. 1978. Flower of Passion. London: Provo.

---. 1986a. Confessions of a young man. London: Penguin.

---. 1986b. Confessions d'un jeune anglais. Paris: Christian Bourgois.

Pierse, M. ed. 2006. George Moore: Artistic Visions and Literary Worlds. Newcastle: Cambridge Scholars Press.

34 Confessions d'un jeune anglais, la versión en francés, sale a la luz tres años más tarde, en 1889. 